\title{
Hospital Equipment and its Management System: A Mini Review
}

\author{
Mercy Adusei Boatemaa* \\ Department of Biomedical Engineering, Faculty of All Nations University College, Ghana
}

Submission: March 28, 2017; Published: July 27, 2017

*Corresponding author: Mercy Adusei Boatemaa, Department of Biomedical Engineering, Faculty of All Nations University College, Ghana, Email: abmercy14@gmail.com

\begin{abstract}
The use of hospital equipment is a vital role to ensure better healthcare service in the country and therefore the need for proper management of hospital equipment in hospitals, clinics, and community centers. Without hospital equipment, there would not be effective operations in health care centers, hospitals, and clinics and as a result of that nurses, doctors and paramedics cannot perform their work properly in saving lives. In places where hospital equipment management is the absence, there would be poor quality healthcare service which leads to high mortality rate of the populace. This paper review on the challenges faced in hospital equipment management in the health sector and the adoption of the five $\mathrm{S}$ management tools into the hospital equipment management system.
\end{abstract}

Keywords: Hospital; Equipment; Management; Doctors; Health care service

\section{Introduction}

The hospital equipment management is a management cycle that starts from planning, procurement, acquisition, installation, commission, decommissioning and finally disposal of hospital equipment [1]. According to Medical Equipment \& Technology Association (META), the term hospital equipment is defined as part of the medical device which is used for it intended medical purposes in hospital care. The hospital equipment requires a routine maintenance and services such as calibration, repair and decommissioning of the equipment inside the hospitals. It is used for diagnosis, rehabilitation, monitoring and treatment of medical conditions and is mostly managed by biomedical engineers or health care technologist. The duty of the biomedical engineer or health care technologist serves as an interface between the doctor and the equipment in facilitating that all hospital equipment present are in good working condition, Yadin et al. [2].

In every well planned hospital facilities and according to WHO, there are some governed policies and procedures that give guidance in selection, planning and acquisition of the hospital equipment which include procedures for the inspection, acceptance, maintenance, equipment breakdown and troubleshooting of the equipment as well as the disposal of the hospital equipment [3]. Association for the Advancement of Medical Instrumentation (AAMI). However, there are some cases where these policies and guidance are inadequately implemented and there must be a way to overcome that in health sectors. The healthcare technology management always ensures that medical equipment and other systems used in healthcare are safe and in good operations and to do so there should be proper management of the equipment to meet the mission and vision of the healthcare. These would also contribute to socio-economic development by promoting health and vitality through access to quality health for all the people. In the absence of proper health technology management system, the health sector would face many challenges. This paper review briefly about the current situation in the absence of medical equipment management system in the health sector and proposed the $5 \mathrm{~S}$ quality management tool as a means for the proper hospital equipment management tool.

\section{The Current Situation on the Challenges Faced by Health Care Technology Management System}

In spite of the hard work of the World Health Organization (WHO) health policies and guidance (World Health Organization, 2011) and the effort of ministry of health in every country, there are many challenges faced in managing the hospital equipment properly, most especially in the developing countries as well as in the rural areas. According to [4]. from Ghana West Africa, the hospital equipment performance as at 1989 was estimated to be 
$64.3 \%$ and a report on the nationwide inventory survey showing decreased percentage in much hospital equipment breakdown. The Challenges involved in hospital equipment management as reported by Zienaa (2009) are the following:

a. Longer downtime of equipment. (Period of time that a system fails to provide or perform its primary function).

b. Hospital administrator's inadequate knowledge on importance on routine hospital equipment maintenance and service.

c. Absence or little budgetary support for maintenance.

d. The lack of the framework for regular auditing system.

e. Lack of knowledge and innovative ways of using new equipment.

f. Delayed fault reporting, example BP Apparatus patch up with plaster.

g. The difficulty in obtaining spare parts.

h. Failure to provide technical training to operators.

i. Obsolete equipment left unattended in maintenance room and wards.

j. The absence of evidence-based information system on health care technology for decision making.

Although most of the challenges and failures mentioned above could be prevented by implementing Planned Preventive Maintenance (PPM) policies as recorded by the procurement process resource guide under WHO medical device technical series [5], but in rural hospitals and places in developing countries, the use of equipment continue without maintenance. If these are not rectified, the hospital equipment getswear out and deteriorate completely. Furthermore, the hospital equipment failures can occur due to various causes. One method of classification classifies them as improper storage and transportation, Initial failure, inappropriate handling, inadequate maintenance, environmental stress, production deficiency, random failure, inappropriate repair technique, and wear-out failure $[3,6]$.

\section{The Five-S Managerial Tool as a Hospital Equipment Management Tool in Health Sector}

The word 5S according to (What Is 5S? - Sort, Set in Order, Shine, Standardize, Sustain) and (5S Comprehensive Education and Resource Center), is simply an acronym of five Japanese words meaning: Seiri, Seiton, Seiso, Seiketsu, and Shitsuke [7]. These are practical steps used in ensuring total quality of work by keeping the workplace in good shape. The Japanese five $S$ methods is a total quality management tool used to organize the workplace in a clean, efficient and safe manner purposefully to enhance productivity and to ensure the level of standardized work by Gapp et al. [8]. It is mainly used by managers in an organization just to engage people with the use of standards and discipline to clean up their workplace. According to Graban [9]. Managers whose propriety is work quality benefits the implementation of the $5 \mathrm{~S}$ as;

A. To improved safety and equipment availability.

B. Improved employee morale.

C. Improved performance in productivity, quality, and morale lead to increased profitability.

D. To serve as the discipline to check and repair equipment.

E. To serve as a better discipline to check reduction in waste and cost.

F. To provide a solid foundation upon which to build continues improvement.

G. Employees gain a sense of ownership, involvement, and responsibility

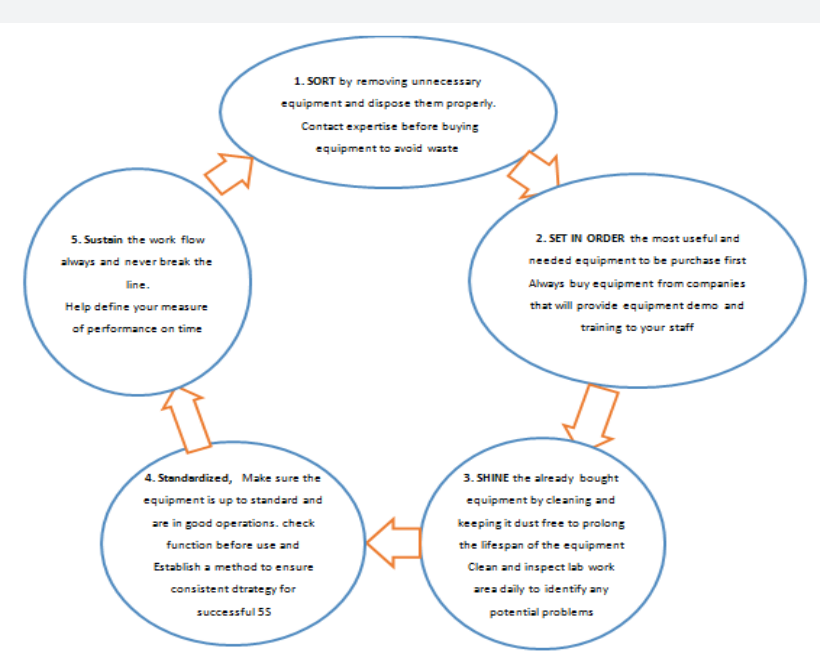

Figure 1: Japanese 5S Tool as a Concept for Hospital Equipment Management Tool for Healthcare Technologist or Biomedical Engineer. 
In this work, a proposed concept of the Japanese $5 \mathrm{~S}$ of the quality tool used for many years by only managers and production companies can also be implemented by healthcare technologist or biomedical engineers for the proper management of the hospital equipment [10-13]. The chart below briefly illustrates how the concept can work, The proposed concept of $5 \mathrm{~s}$ implementation as a hospital equipment management tool (Figure 1).

\section{Discussion}

In developing countries as well as rural areas, it is believed that almost every hospital equipment is being imported creating an arena of many challenges faced by the health sector. The absence of maintenance and repairs of hospital equipment, improper procurement plan, improper calibration, and poor validation of the equipment are the major challenges in hospital equipment management. There could also be a situation where there are inadequate education and effective training for both the hospital administrators and the equipment users on the importance of routine hospital equipment maintenance. Another challenge could also be an inadequate knowledge on how to commission and decommission the hospital equipment and finally improper disposal of the equipment. All these challenges could be overcome by properly implementing the Planned Preventive Maintenance with a proper regulatory body for auditing the hospital equipment system as well as allotting financial budgetary support for maintenance of equipment. Furthermore, the general concept of the $5 \mathrm{~S}$ as a healthcare technology (hospital equipment) tool is that they are intended to eliminate frequent breakdown of hospital equipment and hospital equipment waste from the healthcare sector. It is a simple practical method that instill a quality of work done, which is easy to do and requires no additional resources [14-16].

\section{Conclusion}

The vision and mission statement of every health sector is to have a healthy population for national development and to contribute to socio-economic development by promoting health through access to quality health to all people. Even though the saying goes like to err is human, however, patients and health workers should be free from unnecessary or potential harm associated with the hospital equipment in healthcare. In order to achieve this, there should be a proper hospital equipment management (healthcare technology management) system in every hospital irrespective of size and location of the hospital. The healthcare technology management (hospital equipment management) always ensures that hospital equipment and other systems used in healthcare are safe, operational and a proper maintenance of the equipment to meet the mission and vision of the healthcare.The proposed concept of the Japanese $5 \mathrm{~S}$ to be implemented by healthcare technologist or biomedical engineers for effective management and maintenance of the hospital equipment would serve as the practical way to develop a quality management guideline in healthcare technology to improve standards and quality of hospital equipment management in the health sector. This is because it has the benefit of sorting out, setting in order, sweeping away improper methods, applying standards of health policies and to sustain the good quality culture till quality health delivery is attained.

\section{References}

1. Rajeev B, Ashish D (2007) Healthcare Knowledge Management: Issues, Advances, and Successes, Library of Congress Control Number: 2006923639: 10:0-387-335404.

2. Yadin D, Wolf W, von Maltzahn, Michael RN, Joseph DB, et al. (2003) Clinical Engineering (Principles and Applications in Engineering), CRC Press, USA, p. 432.

3. Khandpur RS (2004) Biomedical Instrumentation: Technology and Applications. McGraw Hills, USA, p. 924.

4. World Health Organization (2011) Introduction to medical equipment inventory management, WHO Medical device technical series.

5. Zienaa, John (2009) Challenges of medical equipment management in Ghana Health Service. CED, HASS, GHS.

6. Dyro, Joseph (2004) Clinical Engineering Handbook (Biomedical Engineering). ( $1^{\text {st }}$ edn), Academic Press, USA, p. 696

7. Hirano, Hiroyuki (1995) 5 Pillars of the Visual Workplace. MA: Productivity Press, Cambridge, USA.

8. Gapp R, Fisher R, Kobayashi K (2008) Implementing 5S within a Japanese Context: An Integrated Management System. Management Decision 46(4): 565-579.

9. Graban, Mark (2012) Lean Hospitals: Improving Quality, Patient Safety, and Employee Engagement. Boca Raton, CRC Press, USA.

10. $5 \mathrm{~S}$ Comprehensive Education and Resource Center.

11. Association for the Advancement of Medical Instrumentation (AAMI).

12. Medical Equipment \& Technology Association (META).

13. Procurement process resource guide. WHO Medical device technical series (2011), World Health Organization (WHO) Press, Switzerland, Geneva.

14. Reporting adverse incidents and disseminating medical device alerts, DB2007, (2007). Medical Device Alert MDA/2007/01, January 2007.

15. What Is 5S? - Sort, Set In Order, Shine, Standardize, Sustain.

16. World Health Organization (WHO) global model regulatory framework for medical devices including IVDs, (2016). A draft for document comment, Working document QAS/16.664, p. 3. 


\begin{tabular}{|l|}
\hline \multicolumn{1}{|c|}{ Your next submission with Juniper Publishers } \\
will reach you the below assets \\
- Quality Editorial service \\
- Swift Peer Review \\
- Reprints availability \\
- E-prints Service \\
- Manuscript Podcast for convenient understanding \\
- Global attainment for your research \\
- Manuscript accessibility in different formats \\
( Pdf, E-pub, Full Text, Audio) \\
- Unceasing customer service \\
Track the below URL for one-step submission \\
https://juniperpublishers.com/online-submission.php \\
\hline
\end{tabular}

